\title{
Effect of Carvedilol vs Metoprolol Succinate on Mortality in Heart Failure with Reduced Ejection Fraction
}

\author{
Tarek Ajam MD, $\mathrm{MS}^{3}$ \\ Samer Ajam MD \\ Srikant Devaraj $\mathrm{PhD}^{4}$ \\ Kahee Mohammed MD, $\mathrm{MPH}^{3}$ \\ Stephen Sawada, MD ${ }^{1}$ \\ Masoor Kamalesh $\mathrm{MD}^{1,2}$ \\ ${ }^{1}$ Krannert Institute of Cardiology Indiana University School of Medicine, Indianapolis, IN \\ ${ }^{2}$ Richard L. Roudebush VA Medical Center, Indianapolis, IN \\ ${ }^{3}$ Saint Louis University School of Medicine, Saint Louis, MO \\ ${ }^{4}$ Ball State University, Indianapolis, IN
}

From: Krannert Institute of Cardiology, Indiana University School of Medicine and Roudebush VA Medical Center, Indianapolis IN 46202

Corresponding Author: Masoor Kamalesh

Address:

$1481 \mathrm{~W} 10^{\text {th }}$ street

Indianapolis IN 46202

Phone 317-988-2401

Fax: 317-988-3531

Email: masoor@aol.com

This is the author's manuscript of the article published in final edited form as:

Ajam, T., Ajam, S., Devaraj, S., Mohammed, K., Sawada, S., \& Kamalesh, M. (2018). Effect of Carvedilol vs Metoprolol Succinate on Mortality in Heart Failure with Reduced Ejection Fraction. American Heart Journal. https://doi.org/10.1016/j.ahj.2018.01.005 


\section{ABSTRACT}

Background: Beta blocker therapy is indicated in all patients with heart failure with reduced ejection fraction (HFrEF) as per current guidelines. The relative benefit of carvedilol to metoprolol succinate remains unknown. This study aimed to compare survival benefit of carvedilol to metoprolol succinate.

Methods: The VA's databases were queried to identify 114,745 patients diagnosed with HFrEF from 2007 to 2015 who were prescribed carvedilol and metoprolol succinate. The study estimated the survival probability and hazard ratio by comparing the carvedilol and metoprolol patients using propensity score matching with replacement techniques on observed covariates. Sub-group analyses were performed separately for men, women, elderly, duration of therapy of more than 3 months, and diabetic patients.

Results: A total of 43,941 metoprolol patients were matched with as many carvedilol patients. The adjusted hazard ratio of mortality for metoprolol succinate compared to carvedilol was 1.069 (95\% Cl: $1.046-1.092$, $p$ value: $<0.001)$. At six years, the survival probability was higher in the carvedilol group compared to the metoprolol succinate group ( $55.6 \%$ vs $49.2 \%$, p value $<0.001)$. The sub-group analyses show that the results hold true separately for male, over or under 65 years old, therapy duration more than three months and non-diabetic patients.

Conclusion: Patients with HFrEF taking carvedilol had improved survival as compared to metoprolol succinate. The data supports the need for furthering testing to determine optimal choice of beta blockers in patients with heart failure with reduced ejection fraction.

Funding: None

Key Words: heart failure, beta blocker, carvedilol, metoprolol succinate 
ABBREVIATIONS

ACC: American College of Cardiology

AHA: American Heart Association

HF: Heart failure

COPD: Chronic obstructive pulmonary disease

HR: Hazard ratio

HbA1c- Glycosylated hemoglobin A1c

ICD-9: International Classification of Diseases, Ninth Revision

ICD: Implantable cardioverter defibrillator

Afib: Atrial fibrillation

CKD: Chronic kidney disease

PAD: Peripheral artery disease 


\section{BACKGROUND}

Beta blocker therapy is indicated in the treatment of all patients with heart failure with reduced ejection fraction (HFrEF) as per current guidelines ${ }^{1-3}$. Overexpression of beta- 1 and beta- $2^{4}$ leads to cardiomyopathy and increased fibrosis and cardiomyocyte apoptosis suggesting their role in heart failure. ${ }^{5}$ Catecholamines trigger alpha- 1 and beta-2 receptors, causing vasoconstriction and vasodilatation, with vasodilation being impaired in heart failure..$^{6-8}$ The three trial-proven beta blockers in the United States for such patients are carvedilol, metoprolol succinate, and bisoprolol. Of these, carvedilol and metoprolol succinate are most commonly used in the United States. Although studies have shown that both beta-blockers are beneficial in reducing mortality and morbidity in HFrEF, there are few data on comparative effectiveness of these medications.

Carvedilol has beta-1, beta-2 and alpha receptor blocking properties, unlike metoprolol succinate which blocks only the beta-1 receptor. ${ }^{1,9}$ The relative benefits of non-selective beta-blockade over cardioselective beta-1 blocker therapy are debatable. ${ }^{10}$ The differential effects of carvedilol and metoprolol on hemodynamics and left ventricular function have been previously described. ${ }^{11,12}$ In the prospective, randomized trial, COMET (Carvedilol or Metoprolol European Trial), carvedilol decreased mortality compared to metoprolol tartrate. ${ }^{13}$ However, this trial was difficult to interpret due to the suggestion of under-dosing with the metoprolol tartrate formulation. The succinate formulation of metoprolol and not tartrate was studied and approved for heart failure.

In this study, a retrospective analysis was conducted on the comparative survival benefits of carvedilol and metoprolol succinate on a large national database of patients with HFrEF.

\section{METHODS}

\section{Study Population}


The Veteran's Affairs (VA) administration provides care for approximately 9 million veterans and their families in the United States. ${ }^{14}$ Patients with HFrEF were identified using International Classification of Diseases $9^{\text {th }}$ Revision (ICD-9) codes. During the period of analysis carvedilol and metoprolol succinate were restricted by the VA pharmacy exclusively for patients with a diagnosis of HF with an ejection fraction less than $40 \%$ in the VA system. Pharmacy consultation is required for a provider to prescribe either medication. The VA's Corporate Data Warehouse (CDW) inpatient, outpatient, and pharmacy databases were queried to identify patients diagnosed with heart failure either as an inpatient or an outpatient from January $1^{\text {st }} 2007$ to January $27^{\text {th }} 2015$ using the VINCI platform. The included patients were required to have filled an outpatient prescription for either carvedilol or metoprolol succinate. The initial start of beta blocker was the recorded date of the first time the medication was filled at a VA pharmacy.

The patients who did not refill the medication through a VA outpatient pharmacy and those who did not take the medication for more than 30 days were excluded. Additionally, the patients who had crossed over to a different beta blocker at any time were excluded. Follow-up duration was defined as the time from the first VA outpatient pharmacy fill date to death or to the end of the study. Beta blocker status prior to the start date of the study was not able to be reviewed.

Our initial sample had 165,159 patients who were treated with either carvedilol or metoprolol succinate. Then observations (excluded subjects) with missing or inconsistent values in sex, treatment start date, duration of treatment, date of birth, and death were removed. Also, the patients who died within 30 days of treatment were removed to prevent other unobserved confounding variables. The observations with the treatment start date outside of our study period and observations with inconsistent coding in diabetes (i.e., diabetic patients without a documented $\mathrm{HbA} 1 \mathrm{C} \geq 6.5 \%$ ) were omitted. A high dosage of 
beta blocker (BB) variable was identified as average daily dose $\geq 25 \mathrm{mg}$ for carvedilol and $\geq 100 \mathrm{mg}$ for metoprolol succinate. ${ }^{15}$

\section{Comorbidities and Outcomes}

All the patients' comorbidities were based on outpatient or inpatient ICD-9 codes. Mortality data was obtained through the VA's death registry. Heart rates were obtained both from outpatient and inpatient settings. Race data was self-reported and was retrieved through the VA databases. Implantable cardioverter-defibrillator (ICD) implantation was defined by Current Procedural Terminology (CPT) codes and ICD-9 codes. Heart rates were obtained both from outpatient and inpatient settings.

\section{Statistical Analysis}

Using Student's t-Test, the means of all variables across both treatment groups were compared. To account for the significant differences in baseline characteristics, comorbidities, and medications between carvedilol and metoprolol, a propensity score matching method to balance the observable covariates was used. Propensity score matching with replacement ensures patients in our sample were comparable on their key observable characteristics to test the differences in mortality among metoprolol and carvedilol patients. Failing to account for matching could lead to significant bias due to unobserved confounders. ${ }^{16}$ The propensity scores were computed by running a logistic regression model, with metoprolol succinate (treated group) as dependent variable, patient characteristics such as age, sex, high dose of BB, comorbidities (presence of an ICD, afib, CAD, kidney disease, COPD, cerebral vascular accident, cirrhosis, deep vein thrombosis, hypertension, obstructive sleep apnea, peripheral arterial disease, pulmonary embolism, smoking status, and diabetes mellitus), and medications (loop

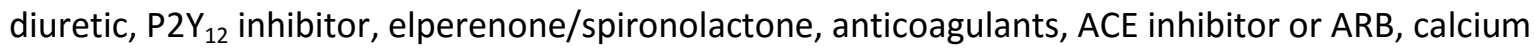
channel blocker, statin, digoxin, nitrate, hydralazine, and aspirin) as control variables. With the propensity scores, a 1:1 matching with replacement was performed. The balance of the matched data 
between carvedilol and metoprolol groups was tested using paired t-test and a $p$ value $>0.01$ for most covariates was considered as an acceptable balance. Among the matched sample, Cox proportional hazard regression models were applied to compare the mortality differences between the two groups. To account for potential misspecification of the model (i.e., error term in the model being not identically distributed), the proportional hazard model with robust standard errors was used.

Several subgroup analyses for different groups were tested for on the matched sample to evaluate the mortality differences between carvedilol and metoprolol. These sub-groups include women, men, African-Americans, over 65 years old, under 65 years old, individuals with therapy duration more than three months, and diabetic vs. non-diabetic sub-groups. For each sub-groups, the hazard ratio of carvedilol versus metoprolol succinate was determined. For robustness tests, the main results were tested with a Poisson model.

All data analyses were performed using STATA 15.0 (StataCorp LP, Texas, USA).

\section{RESULTS}

The original query contained 881,804 veterans, and 165,159 veterans with diagnosis of HFrEF remained after the removal of patients without continuous carvedilol or metoprolol succinate use. After removing veterans with missing information on baseline characteristics or outcomes, the study group was comprised of $114,745 \mathrm{HF}$ patients treated with either carvedilol (61.71\%) or metoprolol succinate (38.29\%). Before matching, the average follow-up time was $3.46 \pm 0.02$ years for carvedilol group and $3.44 \pm 0.02$ years for metoprolol group. The average heart rate for carvedilol group was $74.6 \mathrm{bpm}$ and for metoprolol group was $75.1 \mathrm{bpm}$ prior to matching.

Table 1 shows the comparison of baseline characteristics of metoprolol and carvedilol groups before and after the matching. Prior to matching, we find that most of the variables were significantly different 
from each other. Metoprolol patients were 2.6 years older than carvedilol patients, and more likely to have atrial fibrillation, COPD, hypertension, and peripheral arterial disease than carvedilol patients. Further, they were less likely to have kidney disease, and less likely to smoke than carvedilol patients before matching.

Using 1:1 propensity score matching technique with replacement, 43,941 patients treated with carvedilol were matched with 43,941 patients treated with metoprolol succinate. After matching, the average follow-up time was $3.46 \pm 0.02$ years for carvedilol group and $3.44 \pm 0.02$ years for metoprolol group. After matching, the average heart rate for carvedilol group was $74.4 \mathrm{bpm}$ and for metoprolol group was $75.1 \mathrm{bpm}$. The average daily dose of carvedilol was $17.73 \mathrm{mg}$ and the average daily dose of metoprolol was $103.14 \mathrm{mg}$. The last three columns of Table 1 show the comparison of means of covariates between the carvedilol and metoprolol sample post matching. The baseline characteristics were mostly balanced and there were no significant differences in most of the covariates [26 out of 28 covariates were insignificant at $1 \%$ level] between the two groups. Figure 1 demonstrates the survival curve of carvedilol and metoprolol succinate for the matched sample. At six years, the survival probability was higher in the carvedilol group compared to the metoprolol group (0.556 vs $0.492, p$ value $<0.001$ ).

Table 2 presents the Cox Proportional Hazard results of treatment using metoprolol succinate relative to carvedilol on patients after matching observations based on patient's age, sex, comorbidities, and medications. Model C presents the Cox proportional hazard model results adjusting for patient's age, sex, high BB dose, comorbidities, and medications. The results after propensity score matching show that the unadjusted HR was 1.100 (95\% Cl: 1.077-1.123, p value:<0.01) and adjusted HR was 1.069 (95\% $\mathrm{Cl}: 1.046-1.092, \mathrm{p}$ - value:<0.01). Figure 2 shows the Cox proportional Hazard estimates across different sub-groups on the matched sample (such as sex, race, age group, therapy duration, and presence of 
diabetes). The mortality adjusted for baseline characteristics were higher than 1 for all the sub-groups except for women likely due to the low number of women in this study and diabetes patients. The main results were tested with a Poisson model and consistent results of hazard ratio (HR: $1.125,95 \% \mathrm{Cl}$ : 1.101-1.148, $p$ value:<0.01) were found.

\section{DISCUSSION}

To our knowledge, this is the largest study comparing carvedilol to metoprolol succinate for mortality in patients with HFrEF and includes contemporary patients in a setting outside of the confines of a randomized trial. The study demonstrated that overall, carvedilol use is associated with lower all-cause mortality compared to metoprolol succinate when matched for comorbidities. For the entire matched sample, the mortality rate of metoprolol was $43.1 \%$, whereas the mortality rate of carvedilol was $38.2 \%$ ( $p$ value $<0.01$ ). From Figure 1 , the mortality rates of using carvedilol (our control group) at 4 years posttreatment was 0.25 . From Table 2, we obtain the hazard ratio after adjusting for covariates comparing the metoprolol group (our treatment group) with the carvedilol group as 1.069. Therefore, for every 44 patients treated with metoprolol succinate for four years (after adjusting for covariates) one death will occur beyond those that would have happened when carvedilol is used.

The relative benefits of carvedilol compared to metoprolol succinate remains a matter of debate. It has been hypothesized that the superiority of carvedilol may be attributed to pleiotropic effects on endothelial function, ${ }^{17}$ metabolic, ${ }^{18}$ antioxidant, ${ }^{19,20}$ and antiarrhythmic actions. ${ }^{20}$ The COMET trial, which remains the only large trial comparing carvedilol with metoprolol, showed that carvedilol was superior to metoprolol tartrate in patients with HF. ${ }^{13}$ However, the trial had a limitation in that the heart rates between the two groups were not comparable for the first 16 months thus casting a doubt about direct comparison between the two treatment groups. Additionally, shorter acting metoprolol tartrate was studied in COMET while the mortality benefit of beta blockers in MERIT-HF was 
demonstrated with metoprolol succinate formation which was exclusively analyzed in our study. ${ }^{21}$ The key differences in pharmacokinetics of metoprolol tartrate to the longer acting succinate are characterized by greater peak-to-through fluctuations compared to metoprolol succinate. Metoprolol tartrate reaches high plasma levels 2-3 hours after ingestions, then concentrations and beta blockade fall to lower levels. The sympathetic inhibition reached in the first hours after ingestion of tartrate may limit the increase in the drug doses leading to insufficient B-1 blockade in the subsequent hours. ${ }^{5}$ The average heart rates in COMET trial were 67.7 and $69.3 \mathrm{bpm}$ compared to the averages in this study of 74.4 and $75.1 \mathrm{bpm}$. This may represent that outside of randomized control trials, beta blockers are often under-dosed. A recent meta-analysis also suggested the survival benefit of carvedilol to metoprolol tartrate is lost when compared to metoprolol succinate. ${ }^{22}$ Hence, our comparison of carvedilol to metoprolol succinate can help to fill this gap in the literature.

Since COMET, several smaller database studies have reported on the outcomes in HF patients comparing carvedilol with metoprolol succinate. Our results contrast with a prior smaller study of 3716 subjects done by Shore and co-workers ${ }^{23}$ in which patients with ischemic HF did better on metoprolol succinate while those with nonischemic HF did better on carvedilol. More recently, Fröhlich and colleagues found in a study of 4,016 Norwegian and German outpatients, that there was no difference in mortality in patients taking carvedilol or metoprolol succinate after adjusting for variables and especially medication doses. ${ }^{24}$ Our study included a larger cohort of patients with a substantially longer follow-up period compared to these smaller studies. Similarly, Pasternak and co-workers reported on approximately 11,500 patients from the Danish registry in patients with stable heart failure and showed no difference between the two medications either in the overall cohort or among subgroups. ${ }^{25}$ In contrast, most of our subgroups also showed better survival with carvedilol. A recent meta-analysis of four prospective and six cohort studies showed no difference between the two medications in terms of mortality in the 
overall analysis. ${ }^{22}$ Analyses of randomized prospective trials showed superiority of carvedilol which is mainly driven by the results of COMET. ${ }^{22}$

Contrary to our expectations, diabetics fared better with metoprolol succinate. This may suggest that the beneficial effect of carvedilol on insulin resistance does not translate into clinical benefit. Further studies are required to understand the potential reasons for superiority of metoprolol succinate among diabetes with HF.

The strengths of our study are the large sample size, nationwide distribution, and a long duration of follow-up. Besides the critical elements, the two medications were clinically well matched.

\section{Study Limitations}

Our study has all the limitations of a retrospective analysis. While our data did not include most cardiovascular endpoints, we feel all-cause mortality reduction was the most important endpoint. Although we adjusted for baseline characteristics, not all confounders can be adjusted in a retrospective study. Thus, this study is subject to residual confounding. For instance, we were not able to take into account factors that influence the choice of beta-blockers in HFrEF patients such as patient's tolerance to beta-blocker including blood pressure or clinician's preference. In addition, we were unable to determine the heart failure functional class or severity. Being a VA study, women were underrepresented. Although all subjects had assumed ejection fraction $\leq 40 \%$, given VA restrictions on these medications along with ICD9 diagnosis of HFrEF and similar rates of ICD implantation, individual ejection fraction are not obtained reliably from the database so validation of this assumption was not possible. Estimate of diastolic function could also not be ascertained. In addition, the exact etiology of the reduced ejection fraction was not possible.

\section{Conclusion}


Our study demonstrated that overall patients with HFrEF taking carvedilol had improved survival as compared to metoprolol succinate. The data supports the need for furthering testing to determine optimal choice of beta blockers in patients with heart failure with reduced ejection fraction.

\section{Acknowledgments:}

This material is the result of work supported with resources and the use of facilities at the Richard L. Roudebush VA Medical Center.

The contents of this study do not represent the views of the U.S. Department of Veterans Affairs or United States Government.

Funding: No funding was received.

Disclosures: No conflicts of interests to disclose for all authors.

\section{Clinical Perspectives:}

This study demonstrates an important question for patient care, because there are multiple beta blockers available to treat heart failure. Our data suggest that carvedilol may be considered as first-line therapy in clinical decision making.

\section{Translational Outlook:}

These data support the need for definitive randomized controlled trial examining outcomes and response between carvedilol and metoprolol succinate. 
Figure 1: Kaplan Meier Survival Estimates: Carvedilol versus Metoprolol Succinate on Matched Sample

\section{Carvedilol vs Metoprolol Succinate Survival Estimates}

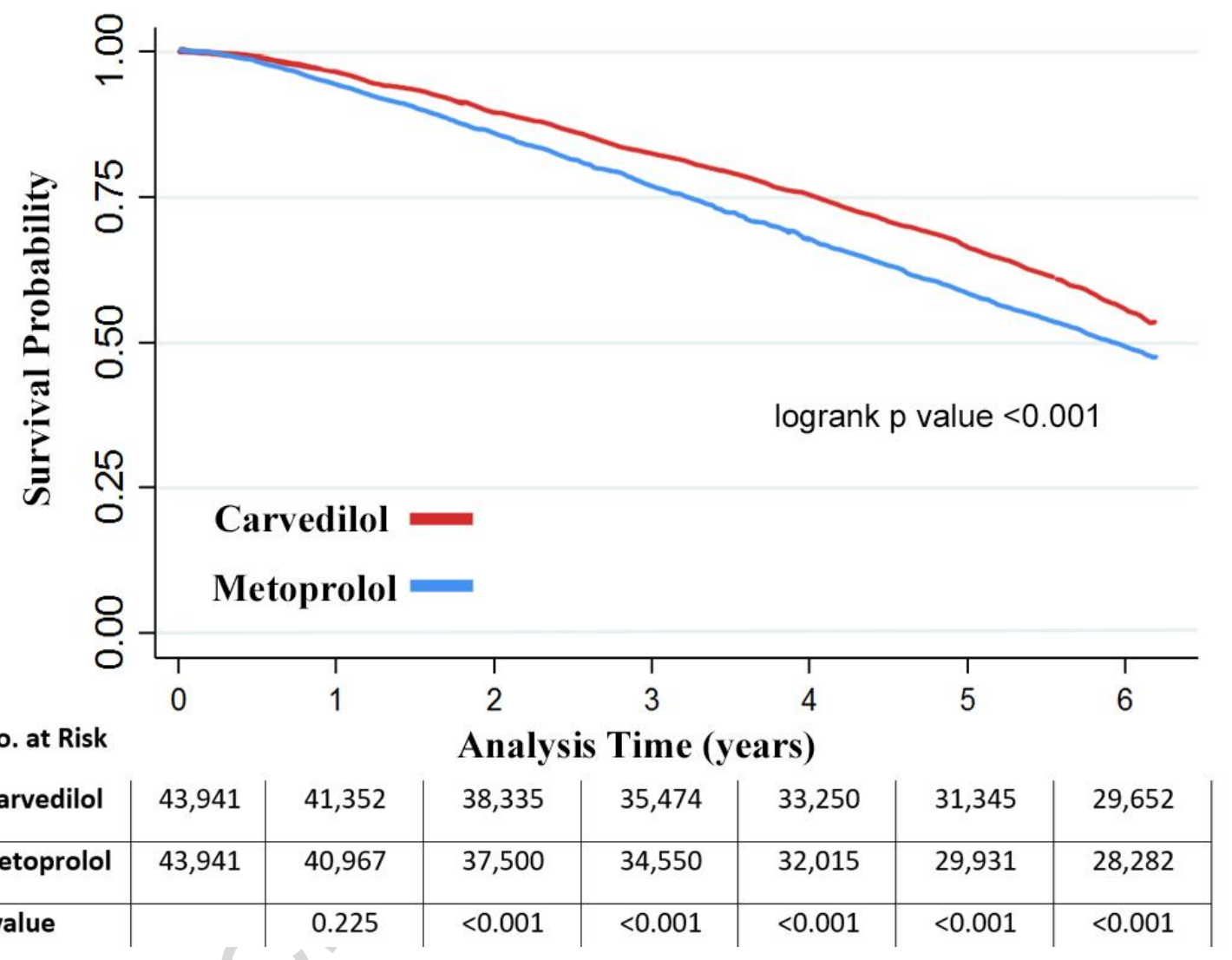

Note: Matched on age, sex, high dose, medications and comorbidities 
Figure 2 Cox proportional Hazard Estimates across Different Sub-groups on the Matched Sample

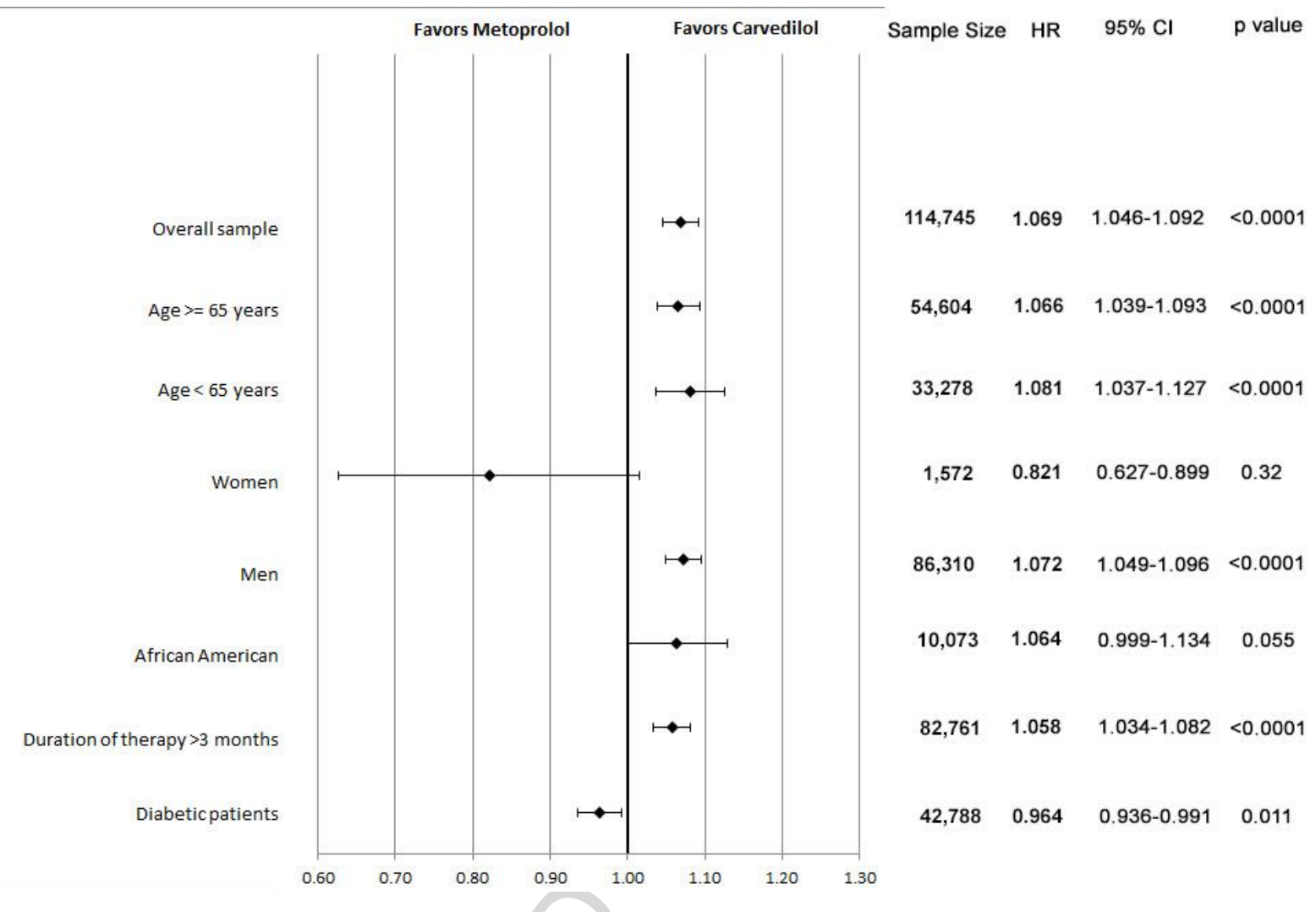

Note: Matched on age, sex, high dose, medications and comorbidities 
Table 1: Comparison of Baseline Characteristics of Metoprolol vs. Carvedilol Group Before and After Matching

\begin{tabular}{|c|c|c|c|c|c|c|}
\hline \multirow[b]{2}{*}{ Variables } & \multicolumn{3}{|c|}{ Pre-matching } & \multicolumn{3}{|c|}{ Post-Matching } \\
\hline & Carvedilol & Metoprolol & $p$ value & Carvedilol & Metoprolol & $p$ value \\
\hline Total & 70,804 & 43,941 & & 43,941 & 43,941 & \\
\hline Age, years & $\begin{array}{c}67.382 \pm \text { SD } \\
11.087\end{array}$ & $\begin{array}{c}69.985 \pm \text { SD } \\
11.018\end{array}$ & $<0.001$ & $\begin{array}{c}70.024 \pm \text { SD } \\
11.131\end{array}$ & $\begin{array}{c}69.985 \pm S D \\
11.018\end{array}$ & 0.602 \\
\hline Women & 0.018 & 0.018 & 0.523 & 0.018 & 0.018 & 0.508 \\
\hline $\begin{array}{l}\text { High BB } \\
\text { Dose }\end{array}$ & 0.427 & 0.585 & $<0.001$ & 0.578 & 0.585 & 0.047 \\
\hline ICD & 0.238 & 0.217 & $<0.001$ & 0.22 & 0.217 & 0.340 \\
\hline $\begin{array}{l}\text { Atrial } \\
\text { fibrillation }\end{array}$ & 0.304 & 0.419 & $<0.001$ & 0.433 & 0.419 & $<0.001$ \\
\hline $\begin{array}{l}\text { Coronary } \\
\text { artery } \\
\text { disease }\end{array}$ & 0.64 & 0.65 & $<0.001$ & 0.653 & 0.65 & 0.305 \\
\hline $\begin{array}{l}\text { Chronic } \\
\text { kidney } \\
\text { disease }\end{array}$ & 0.389 & 0.362 & $<0.001$ & 0.362 & 0.362 & 0.966 \\
\hline COPD & 0.305 & 0.331 & $<0.001$ & 0.333 & 0.331 & 0.505 \\
\hline CVA & 0.12 & 0.117 & 0.141 & 0.113 & 0.117 & 0.032 \\
\hline Cirrhosis & 0.022 & 0.021 & 0.194 & 0.019 & 0.021 & 0.238 \\
\hline DVT & 0.047 & 0.051 & 0.004 & 0.05 & 0.051 & 0.558 \\
\hline $\begin{array}{l}\text { End stage } \\
\text { renal } \\
\text { disease }\end{array}$ & 0.067 & 0.055 & $<0.001$ & 0.054 & 0.055 & 0.407 \\
\hline $\begin{array}{l}\text { Hypertensio } \\
n\end{array}$ & 0.628 & 0.705 & $<0.001$ & 0.702 & 0.705 & 0.408 \\
\hline OSA & 0.171 & 0.17 & 0.481 & 0.17 & 0.17 & 0.829 \\
\hline
\end{tabular}




\begin{tabular}{|c|c|c|c|c|c|c|}
\hline $\begin{array}{l}\text { Peripheral } \\
\text { arterial } \\
\text { disease }\end{array}$ & 0.235 & 0.249 & $<0.001$ & 0.252 & 0.249 & 0.354 \\
\hline $\begin{array}{l}\text { Pulmonary } \\
\text { embolism }\end{array}$ & 0.026 & 0.029 & 0.004 & 0.026 & 0.029 & 0.040 \\
\hline Smoking & 0.255 & 0.239 & $<0.001$ & 0.233 & 0.239 & 0.056 \\
\hline $\begin{array}{l}\text { Diabetes } \\
\text { Mellitus }\end{array}$ & 0.572 & 0.485 & $<0.001$ & 0.489 & 0.485 & 0.160 \\
\hline $\begin{array}{l}\text { Loop } \\
\text { Diuretic }\end{array}$ & 0.802 & 0.761 & $<0.001$ & 0.761 & 0.761 & 0.962 \\
\hline $\begin{array}{l}\mathrm{P}_{2} \mathrm{Y}_{12} \\
\text { inhibitor }\end{array}$ & 0.439 & 0.379 & $<0.001$ & 0.382 & 0.379 & 0.355 \\
\hline $\begin{array}{l}\text { Eplerenone } \\
\text { /Spironolact } \\
\text { one }\end{array}$ & 0.359 & 0.268 & $<0.001$ & 0.268 & 0.268 & 0.951 \\
\hline $\begin{array}{l}\text { Anticoagula } \\
\text { nt }\end{array}$ & 0.313 & 0.392 & $<0.001$ & 0.396 & 0.392 & 0.288 \\
\hline $\begin{array}{l}\text { ACE } \\
\text { inhibitor/AR } \\
\text { B }\end{array}$ & 0.944 & 0.916 & $<0.001$ & 0.912 & 0.916 & 0.040 \\
\hline $\begin{array}{l}\text { Calcium } \\
\text { Channel } \\
\text { Blocker }\end{array}$ & 0.457 & 0.433 & $<0.001$ & 0.432 & 0.433 & 0.728 \\
\hline Statin & 0.9 & 0.89 & $<0.001$ & 0.888 & 0.89 & 0.512 \\
\hline Digoxin & 0.237 & 0.254 & $<0.001$ & 0.253 & 0.254 & 0.692 \\
\hline Nitrate & 0.341 & 0.339 & 0.425 & 0.345 & 0.339 & 0.060 \\
\hline Hydralazine & 0.198 & 0.135 & $<0.001$ & 0.136 & 0.135 & 0.730 \\
\hline Aspirin & 0.605 & 0.614 & 0.001 & 0.614 & 0.614 & 0.956 \\
\hline $\begin{array}{l}\text { Average } \\
\text { Heart Rate }\end{array}$ & $\begin{array}{c}74.595 \pm \text { SD } \\
8.965\end{array}$ & $\begin{array}{c}75.132 \pm \text { SD } \\
9.293\end{array}$ & $<0.001$ & $\begin{array}{c}74.348 \pm \text { SD } \\
8.748\end{array}$ & $\begin{array}{c}75.132 \pm \text { SD } \\
9.293\end{array}$ & $<0.001$ \\
\hline
\end{tabular}


Table 2: Cox Proportional Hazard Ratio of Metoprolol vs. Carvedilol Group Before and After Matching

\begin{tabular}{|c|c|c|c|}
\hline MODELS & \multicolumn{2}{|c|}{ Metoprolol as Treatment Relative to Carvedilol } & $\begin{array}{c}\text { Matched Sample } \\
\qquad=87,882\end{array}$ \\
\hline \multirow{3}{*}{ Model A } & \multirow{3}{*}{ Unadjusted } & Hazard Ratio & 1.100 \\
\hline & & $p$ value & $<0.001$ \\
\hline & & $95 \% \mathrm{Cl}$ & $1.077-1.123$ \\
\hline \multirow{3}{*}{ Model B } & \multirow{3}{*}{$\begin{array}{c}\text { Adjusted with Patient } \\
\text { Characteristics, high BB } \\
\text { dose and Comorbidities }\end{array}$} & Hazard Ratio & 1.073 \\
\hline & & p value & $<0.001$ \\
\hline & & $95 \% \mathrm{Cl}$ & 1.051-1.096 \\
\hline \multirow{3}{*}{$\begin{array}{c}\text { Model C (Preferred Cox } \\
\text { model) }\end{array}$} & \multirow{3}{*}{$\begin{array}{l}\text { Adjusted with Patient } \\
\text { Characteristics, high BB } \\
\text { dose, Comorbidities, } \\
\text { and Medications }\end{array}$} & Hazard Ratio & 1.069 \\
\hline & & $\infty$ & $<0.001$ \\
\hline & & $95 \% \mathrm{Cl}$ & $1.046-1.092$ \\
\hline
\end{tabular}

Note: Matched sample is based on age, sex, high BB dose, comorbidities and medications. 


\section{REFERENCES}

1. Yancy CW, Jessup M, Bozkurt B, Butler J, Casey DE, Jr., Colvin MM, Drazner MH, Filippatos G, Fonarow GC, Givertz MM, Hollenberg SM, Lindenfeld J, Masoudi FA, McBride PE, Peterson PN, Stevenson LW and Westlake C. 2016 ACC/AHA/HFSA Focused Update on New Pharmacological Therapy for Heart Failure: An Update of the 2013 ACCF/AHA Guideline for the Management of Heart Failure: A Report of the American College of Cardiology/American Heart Association Task Force on Clinical Practice Guidelines and the Heart Failure Society of America. J Am Coll Cardiol. 2016;68:1476-88.

2. Ponikowski P, Voors AA, Anker SD, Bueno H, Cleland JG, Coats AJ, Falk V, Gonzalez-Juanatey JR, Harjola VP, Jankowska EA, Jessup M, Linde C, Nihoyannopoulos P, Parissis JT, Pieske B, Riley JP, Rosano GM, Ruilope LM, Ruschitzka F, Rutten FH, van der Meer P and Authors/Task Force M. 2016 ESC Guidelines for the diagnosis and treatment of acute and chronic heart failure: The Task Force for the diagnosis and treatment of acute and chronic heart failure of the European Society of Cardiology (ESC)Developed with the special contribution of the Heart Failure Association (HFA) of the ESC. Eur Heart J. 2016;37:2129-200.

3. Yancy CW, Jessup M, Bozkurt B, Butler J, Casey DE, Jr., Drazner MH, Fonarow GC, Geraci SA, Horwich T, Januzzi JL, Johnson MR, Kasper EK, Levy WC, Masoudi FA, McBride PE, McMurray JJ, Mitchell JE, Peterson PN, Riegel B, Sam F, Stevenson LW, Tang WH, Tsai EJ, Wilkoff BL, American College of Cardiology F and American Heart Association Task Force on Practice G. 2013 ACCF/AHA guideline for the management of heart failure: a report of the American College of Cardiology Foundation/American Heart Association Task Force on Practice Guidelines. J Am Coll Cardiol. 2013;62:e147-239.

4. Du XJ, Gao XM, Wang B, Jennings GL, Woodcock EA and Dart AM. Age-dependent cardiomyopathy and heart failure phenotype in mice overexpressing beta(2)-adrenergic receptors in the heart. Cardiovasc Res. 2000;48:448-54.

5. Santulli $G$ and laccarino $G$. Adrenergic signaling in heart failure and cardiovascular aging. Maturitas. 2016;93:65-72.

6. Sorriento D, Santulli G, Del Giudice C, Anastasio A, Trimarco B and laccarino G. Endothelial cells are able to synthesize and release catecholamines both in vitro and in vivo. Hypertension. 2012;60:12936.

7. laccarino G, Ciccarelli M, Sorriento D, Galasso G, Campanile A, Santulli G, Cipolletta E, Cerullo V, Cimini V, Altobelli GG, Piscione F, Priante O, Pastore L, Chiariello M, Salvatore F, Koch WJ and Trimarco B. Ischemic neoangiogenesis enhanced by beta2-adrenergic receptor overexpression: a novel role for the endothelial adrenergic system. Circ Res. 2005;97:1182-9.

8. Ciccarelli M, Santulli G, Campanile A, Galasso G, Cervero P, Altobelli GG, Cimini V, Pastore L, Piscione $\mathrm{F}$, Trimarco $\mathrm{B}$ and laccarino $\mathrm{G}$. Endothelial alpha1-adrenoceptors regulate neo-angiogenesis. $\mathrm{Br}$ J Pharmacol. 2008;153:936-46.

9. Yoshikawa T, Port JD, Asano K, Chidiak P, Bouvier M, Dutcher D, Roden RL, Minobe W, Tremmel KD and Bristow MR. Cardiac adrenergic receptor effects of carvedilol. Eur Heart J. 1996;17 Suppl B:8-16.

10. Satwani S, Dec GW and Narula J. Beta-adrenergic blockers in heart failure: review of mechanisms of action and clinical outcomes. J Cardiovasc Pharmacol Ther. 2004;9:243-55.

11. Gilbert EM, Abraham WT, Olsen S, Hattler B, White M, Mealy P, Larrabee P and Bristow MR. Comparative hemodynamic, left ventricular functional, and antiadrenergic effects of chronic treatment with metoprolol versus carvedilol in the failing heart. Circulation. 1996;94:2817-25.

12. Sanderson JE, Chan SK, Yip G, Yeung LY, Chan KW, Raymond K and Woo KS. Beta-blockade in heart failure: a comparison of carvedilol with metoprolol. J Am Coll Cardiol. 1999;34:1522-8.

13. Poole-Wilson PA, Swedberg K, Cleland JG, Di Lenarda A, Hanrath P, Komajda M, Lubsen J, Lutiger B, Metra M, Remme WJ, Torp-Pedersen C, Scherhag A, Skene A and Carvedilol Or Metoprolol European 
Trial I. Comparison of carvedilol and metoprolol on clinical outcomes in patients with chronic heart failure in the Carvedilol Or Metoprolol European Trial (COMET): randomised controlled trial. Lancet. 2003;362:7-13.

14. National Center for Veterans Analysis and Statistics. 2014;2015.

15. Fiuzat M, Wojdyla D, Pina I, Adams K, Whellan D and O'Connor CM. Heart Rate or Beta-Blocker Dose? Association With Outcomes in Ambulatory Heart Failure Patients With Systolic Dysfunction: Results From the HF-ACTION Trial. JACC Heart Fail. 2016;4:109-15.

16. Wahba SD, R. Propensity score-matching methods for nonexperimental causal studies Review of Economics and Statistics. 2002;84:151-161.

17. Intengan HD and Schiffrin EL. Disparate effects of carvedilol versus metoprolol treatment of stroke-prone spontaneously hypertensive rats on endothelial function of resistance arteries. $J$ Cardiovasc Pharmacol. 2000;35:763-8.

18. Fonseca V, Bakris GL, Bell DS, McGill JB, Raskin P, Messerli FH, Phillips RA, Katholi RE, Wright JT, Jr., Waterhouse B, Lukas MA, Anderson KM and Investigators G. Differential effect of beta-blocker therapy on insulin resistance as a function of insulin sensitizer use: results from GEMINI. Diabet Med. 2007;24:759-63.

19. Arumanayagam M, Chan S, Tong S and Sanderson JE. Antioxidant properties of carvedilol and metoprolol in heart failure: a double-blind randomized controlled trial. J Cardiovasc Pharmacol. 2001;37:48-54.

20. Ruwald MH, Abu-Zeitone A, Jons C, Ruwald AC, McNitt S, Kutyifa V, Zareba W and Moss AJ. Impact of carvedilol and metoprolol on inappropriate implantable cardioverter-defibrillator therapy: the MADIT-CRT trial (Multicenter Automatic Defibrillator Implantation With Cardiac Resynchronization Therapy). J Am Coll Cardiol. 2013;62:1343-50.

21. Effect of metoprolol CR/XL in chronic heart failure: Metoprolol CR/XL Randomised Intervention Trial in Congestive Heart Failure (MERIT-HF). Lancet. 1999;353:2001-7.

22. Briasoulis A, Palla M and Afonso L. Meta-analysis of the effects of carvedilol versus metoprolol on all-cause mortality and hospitalizations in patients with heart failure. Am J Cardiol. 2015;115:1111-5.

23. Shore S, Aggarwal V and Zolty R. Carvedilol or sustained-release metoprolol for congestive heart failure: a comparative effectiveness analysis. J Card Fail. 2012;18:919-24.

24. Frohlich H, Zhao J, Tager T, Cebola R, Schellberg D, Katus HA, Grundtvig M, Hole T, Atar D, Agewall S and Frankenstein L. Carvedilol Compared With Metoprolol Succinate in the Treatment and Prognosis of Patients With Stable Chronic Heart Failure: Carvedilol or Metoprolol Evaluation Study. Circ Heart Fail. 2015;8:887-96.

25. Pasternak B, Svanstrom H, Melbye M and Hviid A. Association of treatment with carvedilol vs metoprolol succinate and mortality in patients with heart failure. JAMA Intern Med. 2014;174:1597-604. 